\title{
Field-based landslide susceptibility assessment in a data-scarce environment: the populated areas of the Rwenzori Mountains
}

\author{
Liesbet Jacobs $^{1,2}$, Olivier Dewitte ${ }^{1}$, Jean Poesen ${ }^{3}$, John Sekajugo $^{4}$, Adriano Nobile ${ }^{1}$, Mauro Rossi ${ }^{5}$, Wim Thiery ${ }^{6,7}$, \\ and Matthieu Kervyn ${ }^{2}$ \\ ${ }^{1}$ Royal Museum for Central Africa, Department of Earth Sciences, Leuvensesteenweg 13, 3080 Tervuren, Belgium \\ ${ }^{2}$ Vrije Universiteit Brussel, Department of Geography, Earth System Science, Pleinlaan 2, 1050 Brussels, Belgium \\ ${ }^{3}$ KU Leuven, Division of Geography and Tourism, Celestijnenlaan 200E, 3001 Leuven, Belgium \\ ${ }^{4}$ Busitema University, Department of Natural Resource Economics, P.O. Box 236, Tororo, Uganda \\ ${ }^{5}$ CNR-IRPI, Geomorphology division, via Madonna Alta 126, 06128 Perugia, Italy \\ ${ }^{6}$ ETH Zurich, Institute for Atmospheric and Climate Science, Universitaetstrasse 16, 8092 Zurich, Switzerland \\ ${ }^{7}$ Vrije Universiteit Brussel, Department of Hydrology and Hydraulic Engineering, Pleinlaan 2, 1050 Brussels, Belgium
}

Correspondence: Liesbet Jacobs (liesbet.jacobs@vub.be)

Received: 12 July 2017 - Discussion started: 4 August 2017

Accepted: 17 November 2017 - Published: 9 January 2018

\begin{abstract}
The inhabited zone of the Ugandan Rwenzori Mountains is affected by landslides, frequently causing loss of life, damage to infrastructure and loss of livelihood. This area of ca. $1230 \mathrm{~km}^{2}$ is characterized by contrasting geomorphologic, climatic and lithological patterns, resulting in different landslide types. In this study, the spatial pattern of landslide susceptibility is investigated based on an extensive field inventory constructed for five representative areas within the region $\left(153 \mathrm{~km}^{2}\right)$ and containing over 450 landslides. To achieve a reliable susceptibility assessment, the effects of (1) using different topographic data sources and spatial resolutions and (2) changing the scale of assessment by comparing local and regional susceptibility models on the susceptibility model performances are investigated using a pixel-based logistic regression approach. Topographic data are extracted from different digital elevation models (DEMs) based on radar interferometry (SRTM and TanDEM-X) and optical stereophotogrammetry (ASTER DEM). Susceptibility models using the radar-based DEMs tend to outperform the ones using the ASTER DEM. The model spatial resolution is varied between $10,20,30$ and $90 \mathrm{~m}$. The optimal resolution depends on the location of the investigated area within the region but the lowest model resolution $(90 \mathrm{~m})$ rarely yields the best model performances while the highest model resolution $(10 \mathrm{~m})$ never results in significant increases in performance compared to the $20 \mathrm{~m}$ resolution.
\end{abstract}

Models built for the local case studies generally have similar or better performances than the regional model and better reflect site-specific controlling factors. At the regional level the effect of distinguishing landslide types between shallow and deep-seated landslides is investigated. The separation of landslide types allows us to improve model performances for the prediction of deep-seated landslides and to better understand factors influencing the occurrence of shallow landslides such as tangent curvature and total rainfall. Finally, the landslide susceptibility assessment is overlaid with a population density map in order to identify potential landslide risk hotspots, which could direct research and policy action towards reduced landslide risk in this under-researched, landslide-prone region.

\section{Introduction}

Landslide susceptibility assessments aim to estimate the probability of spatial occurrence of landslides given a set of geo-environmental conditions (Guzzetti et al., 2006). Susceptibility maps are fundamental tools for landslide hazard management, assisting governments, scientists or other stakeholders in policy decisions (Fressard et al., 2014). The methods used to achieve these assessments are either knowledge-driven, process-based or statistical in nature 
(Guzzetti et al., 1999). Because statistical, data-driven models provide a quantitative assessment with reasonable data demands, these models are frequently applied on local to regional scales (Corominas et al., 2014). However, while literature is constantly growing with new susceptibility assessment techniques with increasing complexity (Korup and Stolle, 2014), some issues remain unresolved. Firstly, although statistical landslide susceptibility models are often applied, ambiguity remains regarding methodological issues of, among others, landslide sampling, applied resolution and model uncertainty. Secondly, due to increasing computing capacities and the availability of dedicated software tools, landslide susceptibility models are sometimes applied without interpretation of the geomorphologic plausibility of the results (Steger et al., 2016). In addition, for many remote regions, reliable landslide susceptibility assessments are not available despite the potentially large impacts of landslides on the local population in these areas. For example, for the African continent, a systematic lack of investigation of landslides and all their facets is particularly pronounced (Maes et al., 2017). Moreover, while recently landslide susceptibility maps for these regions are issued on various scales ranging from continental (e.g. Stanley and Kirschbaum, 2017) to country-specific (e.g. Redshaw et al., 2017) and local (e.g. Che et al., 2012), the lack of regional and local assessments remains a major limitation in the identification and implementation of effective policy measures (Kervyn et al., 2015).

The Rwenzori Mountains in east Africa are one of those regions where landslides pose a threat to life, livelihood and infrastructure (Jacobs et al., 2016a, b; Mertens et al., 2016). Although this threat is now generally recognized, thus far no quantitative landslide susceptibility assessment is available for the region. Additionally, given the potential role that landslides play in multi-hazard events (Jacobs et al., 2016b), an improved understanding of where landslides are likely to occur is needed.

The primary objective of this work is to identify the factors conditioning the spatial occurrence of landslide events and as such better understand the patterns of landslide susceptibility on regional scale. Studies comparing different susceptibility modelling approaches are frequent and often indicate minor differences between model performances (Dewitte et al., 2010; Zêzere et al., 2017). This research focuses on providing a reliable susceptibility assessment using a logistic regression modelling approach. This requires several methodological choices which will be explored either by consulting previous research findings available in scientific literature, for example with regard to landslide sampling or model construction, or by exploring through simulations the effect of using different sets of topographic data, altering spatial resolution, applying models on different scales and separating landslide types. Therefore, this study aims to also fulfil a methodological objective by investigating the extent to which these factors influence the susceptibility assessment. Based on a critical geomorphological interpretation of these results, the final goal of providing a comprehensive landslide susceptibility assessment for the inhabited region of the Rwenzori Mountains is pursued. This assessment is used to identify which uncertainties regarding landslides' controlling factors remain to be addressed and where potential hotspots for landslide risk may exist.

\section{Study area and landslide inventory}

The Rwenzori Mountains lie on the border of DR Congo and Uganda (Fig. 1). They cover an area of ca. $3000 \mathrm{~km}^{2}$ and reach an altitude of $5109 \mathrm{~m}$ a.s.l. In both countries, the flanks of the mountain are covered by natural vegetation which starts from 1500 to $2000 \mathrm{~m}$ a.s.l. and is largely protected by a pristine national park (Fig. 1). The area of interest for this study is the densely inhabited zone below the national park borders in Uganda. This zone is relatively accessible for field surveys allowing the construction of landslide inventories. To map landslides in these areas, field surveys are required because of the limited possibilities to inventory landslides through remote sensing data interpretation (Jacobs et al., 2017). This limitation is due to the very rapid vegetation recolonization of landslide areas or their reclamation by agriculture combined with a restricted availability of very highresolution optical imagery due to the persistent cloud cover in the humid tropics (Jacobs et al., 2017). The Congolese foot slopes of the Rwenzori are less populated and more difficult to access. Moreover, for the Congolese side of the mountain no reports of landslides were found (Jacobs et al., 2016a).

The populated foot slopes of the Ugandan Rwenzori Mountains, indicated on Fig. 1, cover ca. $1230 \mathrm{~km}^{2}$, including the lowlands in the north-west of the mountain range, where landslide densities are among the highest measured in the region (Jacobs et al., 2017). Because of the large extent of the area of interest, targeted field surveys were conducted in 2014 and 2016, resulting in a landslide inventory for five study areas $\left(153 \mathrm{~km}^{2}\right)$, here referred to as Bundibugyo, Nyahuka, Kabonero, Mahango and Kyondo (Fig. 1). Together they represent all major lithological groups of the study region (Table 1) including rift alluvium, Stanley amphibolite (hereafter referred to as amphibolite), mica schists with quartzitic interbeds (mica schists), TTG gneiss (gneiss) and sericite quartzite and quartzite (quartzite). Kabonero, Bundibugyo and Mahango were inventoried in 2014. The landslide types in these three areas are described in Jacobs et al. (2016b). Nyahuka and Kyondo are two additional areas inventoried in 2016. For these two study areas, maps of the landslide inventories are given as details in Fig. 1. The sliding mechanisms in Kyondo are very similar to those in Mahango and Kabonero where mostly shallow soil and debris slides (estimated sliding plane $<3 \mathrm{~m}$ deep) occur. Nyahuka has similar geomorphological characteristics as Bundibugyo, with a lowland section (with a hilly topography at elevations $<1000 \mathrm{~m}$ a.s.l.) and highlands characterized by metamorphic 


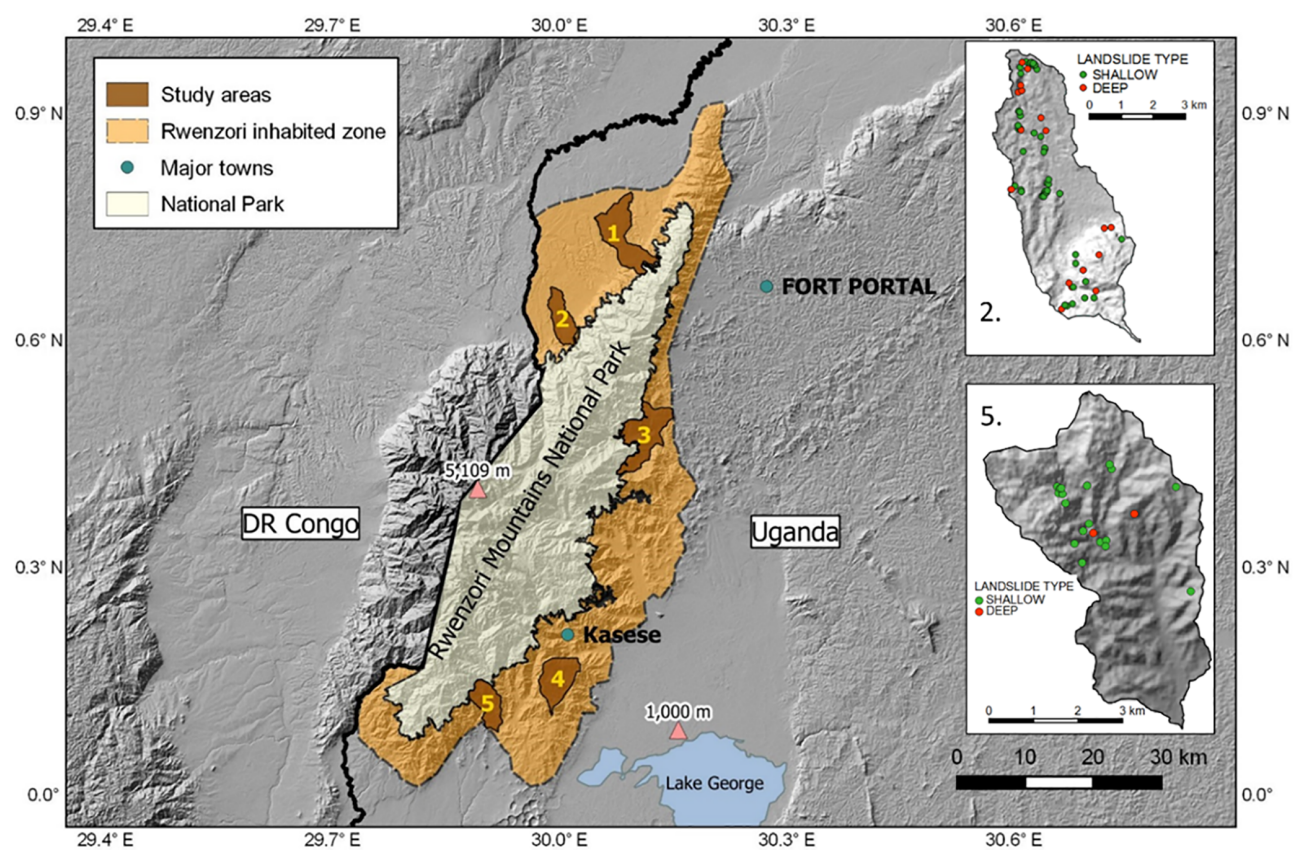

Figure 1. Overview of the surveyed study areas on the Rwenzori foot slopes. The study areas are numbered from north to south: (1) Bundibugyo, (2) Nyahuka, (3) Kabonero, (4) Mahango and (5) Kyondo. For Nyahuka (2) and Kyondo (5) a detailed map is provided showing the locations of shallow and deep-seated slides. Landslide maps of other study areas can be found in Jacobs et al. (2016b).

Table 1. Overview of surveyed study areas (Fig. 1), their surface area and number of total, shallow (SLS) and deep-seated landslides (DSLS) mapped together with the prevailing lithologies in those study areas according to the GTK consortium (2012) and the average annual precipitation as simulated by Thiery et al. (2015).

\begin{tabular}{|c|c|c|c|c|c|c|c|c|}
\hline $\begin{array}{l}\text { Study } \\
\text { area }\end{array}$ & $\begin{array}{r}\text { Area } \\
\left(\mathrm{km}^{2}\right)\end{array}$ & $\begin{array}{r}\text { Elevation range } \\
\text { (m a.s.1.) }\end{array}$ & $\begin{array}{l}\text { Average } \\
\text { slope }\left(^{\circ}\right)\end{array}$ & $\begin{array}{r}\text { No. of } \\
\text { SLS }\end{array}$ & $\begin{array}{l}\text { No. of } \\
\text { DSLS }\end{array}$ & $\begin{array}{r}\text { Total no. of } \\
\text { slides }\end{array}$ & Lithology & $\begin{array}{r}\text { Average } \\
\text { annual } \\
\text { precipitation } \\
(\mathrm{mm})\end{array}$ \\
\hline Bundibugyo & 42.6 & $715-2200$ & 12 & 83 & 125 & 208 & $\begin{array}{l}\text { rift alluvium, mica schists, } \\
\text { gneiss }\end{array}$ & 1010 \\
\hline Nyahuka & 20.4 & $830-2200$ & 12 & 48 & 17 & 65 & $\begin{array}{l}\text { rift alluvium, mica schists, } \\
\text { amphibolite, gneiss }\end{array}$ & 1540 \\
\hline Mahango & 29.6 & $1240-2200$ & 20 & 69 & 22 & 91 & gneiss & 930 \\
\hline Kyondo & 20.4 & $1130-2140$ & 20 & 18 & 2 & 20 & gneiss, quartzite, mica schists & 1040 \\
\hline Total & 153 & & & 271 & 183 & 454 & & \\
\hline
\end{tabular}

rock. The lowlands in the Bundibugyo study area are dominated by deep-seated rotational soil slides occurring preferentially in thick deposits of rift alluvium. In Nyahuka, however, shallow landslides prevail. A summary of the surveyed study areas, their areal extension, numbers of shallow and deep-seated landslides, their main lithologies and their average annual precipitation depth is given in Table 1. Rainfall is the main trigger of landslides in the region with only 14 landslides reported to be earthquake triggered. In total this inventory contains 454 landslides which are used for the sus- ceptibility modelling. More details on the landslide inventory construction can be found in Jacobs et al. (2016b).

\section{Methodology}

A pixel-based logistic regression model is applied to assess landslide susceptibility of the study area using landslide occurrences derived from the landslide inventory as the dependent variable. The logistic regression model is a widely applied statistical approach for predicting dichotomous depen- 


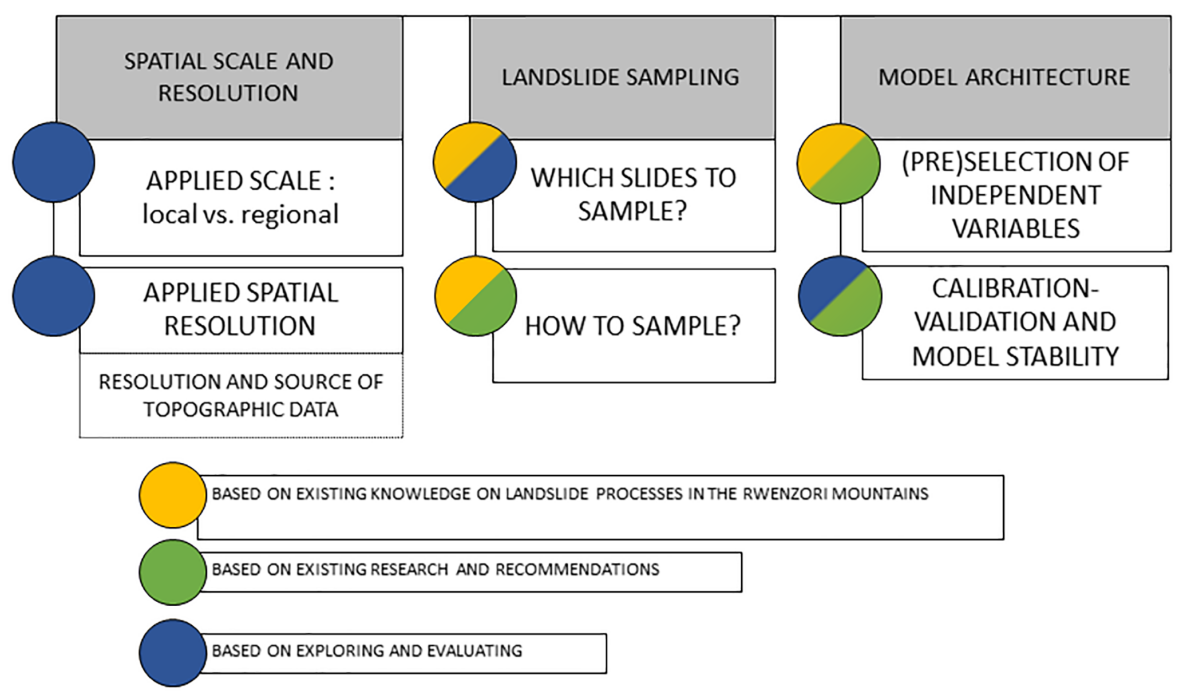

Figure 2. Schematic representation of the methodological options considered in this study and how they are evaluated and selected.

dent variables, such as the presence or absence of landslides (Hosmer and Lemeshow, 2004; Brenning, 2005):

$$
\begin{aligned}
& P(y=1)= \\
& \frac{1}{(1+\exp -(\alpha+\beta 1 X 1+\beta 2 X 2+\ldots+\beta n X n))},
\end{aligned}
$$

where $y$ is the dichotomous variable indicating the presence or absence of a landslides, $X i$ the explanatory variables considered by the model and $\beta i$ the coefficients assigned to each explanatory variable $X i$. The output probability values range from 0 to 1 , corresponding to a 0 to $100 \%$ spatial probability of a landslide occurrence. The logistic regression has the advantage of enabling a straightforward interpretation of which independent variables contribute to the prediction and how they do so (Tu, 1996).

When applying a pixel-based statistical landslide susceptibility model such as the logistic regression model, several methodological choices need to precede the construction of the model and the final susceptibility assessment. These methodological choices can notably include the scale of the assessment, the model's spatial resolution (e.g. Catani et al., 2013; Tian et al., 2008), the subdivision between model calibration and validation data (e.g. Heckmann et al., 2014; Hussin et al., 2016) and the landslides sampling strategy (e.g. Nefeslioglu et al., 2008; Yilmaz, 2010). The motivations behind these methodological choices are not always given, limiting the reproducibility of the analyses and the extent to which obtained results can be critically evaluated.

In the following sections the methodological choices made for our specific case study are specified. Where possible this is based on recommendations found in key methodological research and available knowledge on landslide processes in the Rwenzori region. These choices are summarized in Fig. 2 and further explored below. For choices that depend on the characteristics of the case study, such as the applied scale and spatial resolution of the assessment, the topographic data source used or the landslide type subdivision, several scenarios are simulated and the outcomes evaluated. This evaluation considers jointly (1) the performance and stability of the resulting model and (2) the degree to which the resulting model can be interpreted and reflects a geomorphologic reality. First, choices regarding the applied spatial scale and resolution and related topographic data source are explored. Afterwards, the model construction itself is further discussed with regard to the landslide sampling strategy, the landslide type subdivision, the model variable selection and the model calibration and validation. Subsequently, the model evaluation method is specified. Finally, the assessment of potential landslide risk hotspots based on the regional landslide susceptibility map is discussed.

\subsection{Selection of spatial resolution, topographic data source and spatial scale of the analysis}

In studies using pixel-based landslide susceptibility models, the choice of model's spatial resolution is often motivated based on the resolution of the available data sets, with a preference for using the most finely gridded resolution possible. In the context of statistical landslide susceptibility assessments, only a few studies compared different model resolutions (e.g. Catani et al., 2013; Tian et al., 2008). Additionally, because of the availability of multiple global digital elevation models (DEMs) such as the Shuttle Radar Topography Mission (SRTM DEM; NASA JPL., 2013), DEMs derived from optical ASTER imaging (ASTER DEM; METI/NASA, 2009) and often also DEMs derived from local topographic data, more than one source of topographic information is available for landslide studies. Despite this, these various topographic information sources are rarely compared (e.g. 
Havenith et al., 2006). In the data-scarce setting of the Rwenzori Mountains, the selection of the most appropriate model resolution and topographic data source is particularly relevant. Here, to model landslide susceptibility, three different topographic information sources are used at four different resolutions.

The SRTM and ASTER DEMs are freely available online for most parts of the world. They are downloaded at the provided $1 \operatorname{arcsec}(\sim 30 \mathrm{~m})$ resolution (METI/NASA, 2009; NASA JPL., 2013). The third topographic source is a TanDEM-X DEM (Deo et al., 2013). This DEM is constructed at a $\sim 5 \mathrm{~m}$ resolution with the InSAR technique (Interferometric Synthetic Aperture Radar; Bürgmann et al., 2000; Hanssen, 2001) using TanDEM-X bi-static images (Moreira et al., 2004) acquired in ascending and descending orbit. More background on the TanDEM-X DEM construction can be found in Appendix A. The final TanDEM-X DEM is resampled to a $10 \mathrm{~m}$ resolution with subsequent aggregation to 20 and $30 \mathrm{~m}$ resolution using weighted aggregation (Grohmann, 2015). The ASTER DEM and SRTM DEM $1 \mathrm{~s}$ are resampled to precisely 30 by $30 \mathrm{~m}$ DEMs using bicubic resampling (Metz et al., 2010). Similar to the TanDEM-X, the SRTM30 is up-scaled to $90 \mathrm{~m}$ using weighted aggregation resampling. The variants based on TanDEM-X DEMs are hereafter referred to as TANDEMX10, 20 and 30, those based on SRTM as SRTM30 and 90 and those on ASTER DEM as ASTER30. While the TanDEM-X DEM and the SRTM are based on InSAR data, the ASTER DEM is produced by stereophotogrammetry principles. By testing all three DEMs at the $30 \mathrm{~m}$ pixel size, the DEM suitability regardless of the pixel size can be assessed. Thus in total six different combinations of DEM sources and resolutions are tested. Henceforth they are referred to as model variants.

In this study, the dependency of the model on the spatial scale of the assessment is also assessed. This is achieved by building models at the local level for individual case studies (ca. $20-43 \mathrm{~km}^{2}$ ) and at the regional level for all case studies combined $\left(153 \mathrm{~km}^{2}\right)$. Mahango and Kyondo are investigated together on the local scale due to their proximity and given the low number of landslides in Kyondo. Kabonero, Bundibugyo and Nyahuka are investigated separately on the local scale. These four local scales and the regional scale are hereafter referred to as levels. The model combining all case study areas thus makes use of the landslide data of all case studies, which combined are considered to be representative for the Rwenzori inhabited zone. It should be noted that the calibration and validation are performed within the surveyed area boundaries and that outside the surveyed areas the susceptibility assessment should be considered as an extrapolation of the statistical model.

\subsection{Model construction}

\subsubsection{Landslide sampling}

The sampling of landslides for pixel-based susceptibility modelling is not a well-defined procedure, and different approaches exist to select those pixels best representing the conditions under which the landslide occurred. While some studies take the whole polygon defining the landslide boundaries as input, others consider either the centroid, a portion of the highest pixels within the landslide, the source area or construct a seed cell zone around (portions of) the landslide to represent the conditions under which the landslide occurred (e.g. Dai and Lee, 2003; Suzen and Doyuran, 2004; Van den Eeckhaut et al., 2006; Che et al., 2012; Hussin et al., 2016).

Here, the approximate location of the landslide depletion zones was identified in the field and is thus available in the inventory (Jacobs et al., 2017). Although selecting all pixels within the depletion zone generally provides better model fits (e.g. Hussin et al., 2016; Yilmaz, 2010), this is likely an artefact due to the introduction of very similar pixels within the model (Hussin et al., 2016). Additionally, it can induce spatial autocorrelation, violating the assumption of independent observations for general linear models (Van Den Eeckhaut et al., 2006). Although some models take this into account, they are reported to be numerically more demanding and less stable (Brenning, 2005). Therefore, in order to avoid spatial autocorrelation and equally consider landslides regardless of their size, only the centroid of the depletion zone is used to represent the event.

\subsubsection{Landslide type distinction}

As described in Sect. 2, the Rwenzori Mountains host a diversity of landslide types. Because each landslide type is expected to be controlled by a different set of explanatory variables or a different effect of those variables, separating the types is a meaningful procedure in landslide susceptibility assessment. However, by doing so, sample sizes are reduced and statistical significance can be lost. In this study, the effect of separating landslide types between the deep-seated (depth of sliding plane $>3 \mathrm{~m}$ ) and shallow landslides (depth sliding plane $<3 \mathrm{~m}$ ) is compared at the regional level. The depth of the sliding plane was estimated in the field (Jacobs et al., 2017). The separation of shallow and deep-seated landslides at the regional level allows us to maintain reasonable sample sizes.

\subsubsection{Variable selection}

From previous exploratory work on landslide data collected in the region, topographic and lithological variables appear to have considerable effects on landslide types and spatial distributions (Jacobs et al., 2017). The topographic information extracted from the three different DEMs described in Sect. 3.1 are slope, elevation, profile and tangent curvature, 
the aspect and the topographic wetness index (TWI) defined as the natural logarithm of the ratio of the specific upstream contributing area over the tangents of the slope (Beven and Kirkby, 1979). The TWI serves as a proxy for spatial soil moisture patterns in the landscape (Yilmaz, 2010). The aspect is considered as the sine and cosine of both the aspect expressed as degrees counterclockwise of east to express maximum differences in the north-south and east-west axes, respectively, as well as the aspect in degrees counterclockwise of north-east to express maximum differences between north-west and south-east as well as north-east and south-west, respectively (Chang et al., 2007; Stage and Salas, 2007). Information on the lithology is extracted from the lithological map of Uganda at $1: 100000$ (GTK Consortium, 2012; Table 1) and converted to dummy variables with gneiss used as the reference lithology, i.e. each lithological class is compared to gneiss (Dai and Lee, 2002; Goverski et al., 2006).

Detailed land use mapping serving as input for the landslide susceptibility model is in this study not feasible due to the complexity (multiple cropping and multi-layered) and dynamics of the land use with regard to agricultural crops (rapid alterations due to a bimodal rainfall pattern). However, especially for shallow landslides, a stabilizing effect of trees on the soil could be expected. Therefore, at the regional level where shallow and deep-seated landslides are separated, the tree-cover percentage as calculated by Hansen et al. (2013) for the baseline year of 2000 is introduced into the model for shallow landslides. Additionally, for all regional simulations, annual average precipitation data on a $7 \times 7 \mathrm{~km}^{2}$ grid obtained by the COSMO-CLM ${ }^{2}$ regional climate model, covering a period from 1998-2008, are used to analyse the effect of spatial precipitation distribution on landslide susceptibility (Thiery et al., 2015). Due to the relatively large pixel size of this data set compared to the area of the case studies, the risk exists that single pixels in the precipitation data set completely control precipitation amounts in the case studies. To avoid this, a 3-by-3 moving average filter is applied to the precipitation data set in order to represent regional precipitation patterns. Finally, although elevation is commonly used in landslide susceptibility models, its value in our regional model can be questioned. Elevation is often introduced as a proxy for rainfall depth and/or weathering (Coe et al., 2004; Dai and Lee, 2003), with the assumption that higher elevations are linked to more rock weathering, leading to a weaker lithology. However, in the Rwenzori, rainfall distribution at the regional level is strongly linked to prevailing climatic systems not represented by the elevation alone (Thiery et al., 2015; Jacobs et al., 2016a). Furthermore, precipitation is already introduced in the regional model as an explanatory variable. In addition to this, at the regional level, low elevation is expected to reflect mostly higher landslide densities observed on a rift alluvium lithology rather than serving as a proxy for spatial rainfall patterns, as higher elevations are linked to more resistant lithological groups (Table 1, Jacobs et al., 2017), which are already introduced into the model. Therefore, in the regional model assessments, no strong arguments support the use of elevation as an explanatory variable. For completeness, the regional models are run both with and without elevation.

The final variable selection at all levels and variants is performed by a stepwise selection procedure applied to all variables except the categorical variable of lithology for which all dummies are considered together in the model (Agresti, 2003; Heumann et al., 2017). Forward, backward and bothway stepwise selections are performed and the selection procedure for the final model and its variables is based on a minimization of the Akaike information criterion (AIC), which penalizes models with a large number of parameters and models with poor fit (Goetz et al., 2011).

\subsubsection{Model calibration and validation and implications for stability}

Similarly to landslide sampling, different approaches exist for separating the landslide inventory into a calibration and validation data set. In most cases, the training data set is chosen to be equal or slightly bigger than the validation set with $50-50,75-25$ or $60-40 \%$ as common subdivisions. Studies comparing model performances at different subdivisions tend to show that a minimum of $10-20 \%$ of the landslides for the calibration is required, after which an increase does not significantly improve the modelling results (Hussin et al., 2016). Therefore, in this study, for each variant, the landslides in the inventory are split randomly in equally proportionate data sets equally serving in the calibration and validation stages, respectively. Because this random split could influence the model construction, especially in these case studies dealing with small landslide data sets, this procedure is repeated 20 times for each model variant at each level to verify its stability. Pixels where no landslide occur are considered to be all the pixels in the study areas outside the landslide polygons. An equal portion of landslide and non-landslide pixels is used in the model calibration stage (e.g. Brenning, 2005; Hussin et al., 2016). All other pixels are used in the validation stage.

\subsection{Assessment of model performances and comparisons}

The above methodology results in a set of models of which performances are influenced by the topographic data source used, the applied resolution and represented scale. To assess the effect of these factors, first the model variants are compared within each level, after which the regional level is compared to the local ones.

The evaluation of model performances using the different topographic data sources and various spatial resolutions at each level (model variants) is based on the comparison of the model fit in terms of $\mathrm{AUC}_{\mathrm{ROC}}$, a summary statis- 
tic indicating the model performance corresponding to the area under the receiver-operating characteristics curve which combines both sensitivity and specificity (Fawcett, 2006). $\mathrm{AUC}_{\mathrm{ROC}}$ values of 1 indicate a perfect model fit, while values of 0.5 indicate that the model is not performing better than a random distinction. Generally, models with $\mathrm{AUC}_{\mathrm{ROC}}$ values greater than 0.7 are considered to have an acceptable model performance (Fressard et al., 2014). The repeated random sampling of landslides for the calibration and validation of the models explained in Sect. 3.2.4. results in a sample of $20 \mathrm{AUC}_{\mathrm{ROC}}$ values per model variant. For each level, the performance differences between (1) all variants of DEMs and resolutions tested, (2) the three different TanDEM-X variants, (3) the two different SRTM variants and (4) the three different variants on the $30 \mathrm{~m}$ resolution are assessed. The tests used for this depend on whether or not the assumption of normality and homoscedasticity can be made. Therefore, the distribution of $\mathrm{AUC}_{\mathrm{ROC}}$ values for all model variants is first tested for normality using the Shapiro-Francia test (Thode, 2002). Afterwards, homoscedasticity is tested for each comparison using the Levene test and the FlignerKilleen test for normal and non-normal distributions, respectively (Conover et al., 1981; Glass 1966). For comparisons of variants that are normally distributed and homoscedastic, the ANOVA single-factor tests are used to compare mean performances over more than two variants, while Student's $t$ tests are used to evaluate the difference between mean performances of two variants (Lowry, 2014). For non-normal distributions that are homoscedastic, non-parametric tests comparing variant's sample medians are introduced to complement the parametric tests: the Kruskal-Wallis test to compare more than two model variants and the Mann-Whitney $\mathrm{U}$ test to directly compare two variants (Lowry, 2014). In case variants are found to be heteroscedastic, an additional Welch test is performed to investigate the difference between variants (Welch, 1951). Based on these assessments, variants for each applied level (local and regional) will be selected. To further evaluate these selected variants' model predictive skill, sensitivity, specificity and prediction curves are considered separately (Guzzetti et al., 2006; Van Den Eeckhaut et al., 2009).

For the evaluation of the effect of applied scale on the susceptibility assessment, a pairwise comparison of the regional model to the different local models is performed visually and in terms of the variables selected within each model. To quantitatively assess the ability of the selected regional model to predict local landslide susceptibility, the regional model is additionally validated using the local data set of landslides and non-landslides at each local level after removal of the points used for the regional model's calibration. This performance of the regional model validated at the individual local levels is compared to the performance of the regional level validated at all the local levels combined. Discrepancies surfacing through these comparisons will allow us to identify potential strengths or limitations of the application of the regional model to the entire inhabited zone.

\subsection{Regional landslide susceptibility assessment and preliminary identification of risk hotspots}

Landslide susceptibility and risk zonation are particularly rare in equatorial Africa but all the more relevant to the focus of research and policy action (Kervyn et al., 2015). Here, the regional landslide susceptibility and population density distribution are combined to provide a preliminary identification of landslide risk hotspots. The regional susceptibility model for the Rwenzori Mountains is obtained by applying all 20 simulations of the optimal model variant and averaging the resulting susceptibility values. Subsequently, parish population density data for the year 2002 provided by the Uganda Bureau of Statistics (UBOS, 2003) are rescaled to continuous values between 0 and 1 . By multiplying the rescaled population density with the regional landslide susceptibility, a first identification of potential landslide risk hotspots can be made. Evidently, the approach applied here is rough and among others does not account for within-parish population concentration, temporal aspects of the landslide occurrence or vulnerability or resilience of the population to the occurrence of a landslide event. The goal is not to present a risk assessment but to explore where hotspots for landslide risk could possibly occur and consequently which regions require particular attention when considering landslide risk assessments.

\section{Results}

\subsection{Influence of model's spatial resolution, topographic data source and applied scale}

Variants' model performances for each level in terms of mean and standard deviation of the $\mathrm{AUC}_{\mathrm{ROC}}$ in the validation is given in Table 2. With regard to the regional model, no overall statistical difference between model variants with and without the introduction of elevation is found ( $t$ test, $p<0.05)$. Therefore, the regional model without elevation is used throughout this study. At the regional level and all local levels, the null hypothesis that all models variants have the same performance can be rejected (Table 2). When comparing the DEMs at $30 \mathrm{~m}$ at any level, ASTER30 never produces the best model results (Table 2). Similarly, the SRTM90 performs significantly worse than SRTM30 at the regional and all local levels with the exception of Nyahuka, where the SRTM90 outperforms the SRTM30 (Table 2). With regard to the optimal resolution of the TanDEM-X variants, there is only a significant difference between TanDEM- $X$ variants in Nyahuka and Kabonero. The increase in resolution from 20 to $10 \mathrm{~m}$ is tested separately and does not increase performances at any level $(p<0.05)$. 
Table 2. Overview of the mean and standard deviation (SD) of $\mathrm{AUC}_{\mathrm{ROC}}$ over 20 runs for the different model variants at each level. Selected model variants are marked in bold, and values in italic indicate non-normally distributed samples (Shapiro-Wilk test, $p<0.05$ ). Wherever applied, all non-parametric tests and the Welch test confirm the results of the parametric tests and results are therefore combined here. Symbols indicate significant differences detected between variants.

\begin{tabular}{|c|c|c|c|c|c|c|c|}
\hline & & TANDEMX10 & TANDEMX20 & TANDEMX30 & ASTER30 & SRTM30 & SRTM90 \\
\hline Regional & Mean AUC $\mathrm{ROC}_{\mathrm{R}}$ & 0.71 & 0.71 & 0.71 & 0.68 & 0.71 & 0.68 \\
\hline$\diamond / \bigcirc / \Delta$ & SD AUC $\mathrm{ROC}$ & 0.01 & 0.01 & 0.01 & 0.01 & 0.01 & 0.02 \\
\hline Bundibugyo & Mean AUC ${ }_{\text {ROC }}$ & 0.70 & 0.69 & 0.70 & 0.63 & 0.70 & 0.65 \\
\hline$\diamond / \bigcirc / \Delta$ & $\mathrm{SD} \mathrm{AUC}_{\mathrm{ROC}}$ & 0.03 & 0.02 & 0.01 & 0.03 & 0.02 & 0.02 \\
\hline Nyahuka & Mean AUC $\mathrm{ROC}_{\mathrm{R}}$ & 0.69 & 0.69 & 0.64 & 0.66 & 0.69 & 0.75 \\
\hline$\diamond / \square / \Delta$ & $\mathrm{SD} \mathrm{AUC}_{\mathrm{ROC}}$ & 0.04 & 0.03 & 0.06 & 0.06 & 0.05 & 0.05 \\
\hline Kabonero & Mean AUC ${ }_{\text {ROC }}$ & 0.75 & 0.78 & 0.76 & 0.75 & 0.75 & 0.69 \\
\hline$\diamond / \square / \Delta$ & SD AUC $\mathrm{ROC}$ & 0.05 & 0.04 & 0.03 & 0.05 & 0.05 & 0.05 \\
\hline Kyondo/Mahango & Mean $\mathrm{AUC}_{\mathrm{ROC}}$ & 0.71 & 0.73 & 0.71 & 0.68 & 0.73 & 0.66 \\
\hline$\diamond / \bigcirc / \Delta$ & SD AUC ROC & 0.04 & 0.04 & 0.03 & 0.05 & 0.03 & 0.04 \\
\hline
\end{tabular}

Significant difference between all variants $(\diamond$ at $p<0.05)$. Significant difference between TanDEM-X variants $(\square$ at $p<0.05)$. Significant difference between all variants at $30 \mathrm{~m}(\bigcirc$ at $p<0.05)$. Significant difference between SRTM variants $(\Delta$ at $p<0.05)$.
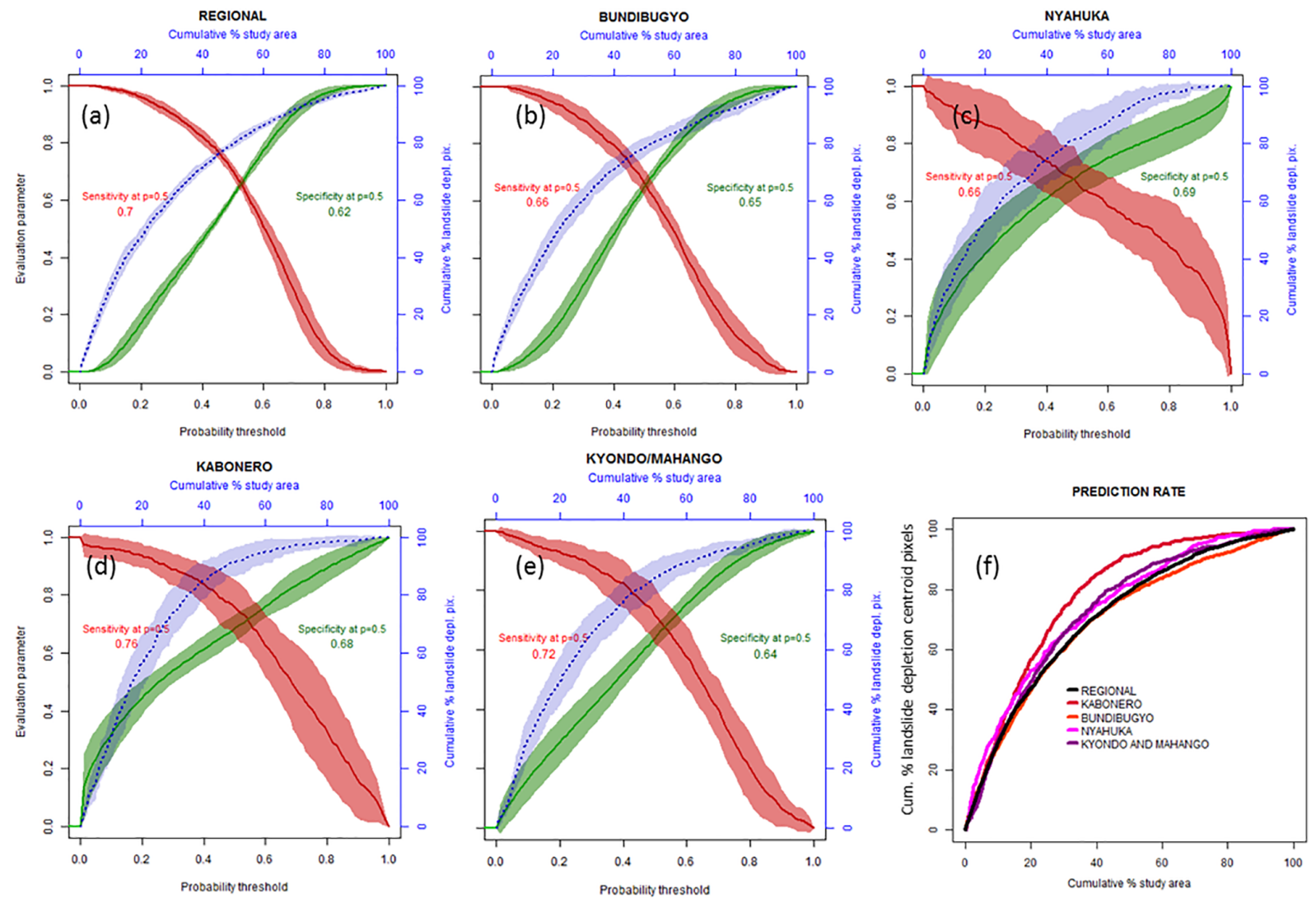

Figure 3. Model performance indicators for the selected model variants (indicated in bold in Table 2). (a-e) Sensitivity (red), specificity (green) and prediction rate curve (blue). (f) Mean prediction rates for selected models at the regional and local levels.

Table 2 also indicates that the best-performing local models with the exception of Bundibugyo have better performances than the best regional model in terms of $\mathrm{AUC}_{\mathrm{ROC}}$.
At the local level, the best performing model variant depends on the location of the case study area but, in most cases, no single model variant significantly outperforms an- 
other. Only in Nyahuka does one variant - SRTM90 - clearly outperform the others. In Kabonero and Kyondo/Mahango, the TANDEMX20 is preferred and the SRTM30 provides the best results for Bundibugyo. For the local levels, the variant with the highest $\mathrm{AUC}_{\mathrm{ROC}}$ is selected and indicated in bold in Table 2. Because of the potential influence of the accuracy of the TanDEM-X DEM on the regional susceptibility assessment outside the studied zones, the consistent performance of the SRTM DEM and the lack of performance difference between the TanDEM-X variants and the SRTM30, the SRTM30 variant is selected as the basis for the regional landslide susceptibility map. For the regional and all local levels, the selected model variants are further explored in terms of sensitivity, specificity and prediction rate (Fig. 3). The results show that also for these performance indices, generally, the local models outperform the regional model with the exception of model sensitivity in Nyahuka and Bundibugyo and model prediction rate in Bundibugyo. However, the variation on these model evaluators between simulations for the local models is also larger than that for the regional model.

Based on these results, the selected variants are interpreted in terms of their selected variables. Table 3 summarizes how many times over the 20 simulations a certain explanatory variable is selected by the model variant indicated in bold in Table 2, which sign the corresponding $\beta$ value has, and how often these variables are considered to be significant in the logistic regression. Slope is a significant contributor in all study areas and in nearly all runs. Elevation plays different roles at the local levels with a positive influence on the occurrence of landslides within Kyondo/Mahango. TWI has a positive response in the landslide susceptibility assessment in Nyahuka and to a lesser extent in Kyondo/Mahango, while the opposite is observed in Kabonero. Aspect only seems of limited importance in the Bundibugyo where south-east-facing slopes appear more landslide-prone than north-west-facing slopes. Profile concave slopes favour landslides in Nyahuka while profile convex slopes favour landslides in Kabonero and Bundibugyo. Finally, tangent concave slopes favour landslides on the regional level, in the typical highland regions of Kabonero and - to lesser extent - of Kyondo/Mahango.

With regard to lithology, some classes have a more readily interpretable behaviour than others. Rift alluvium is invariably found to be positively indicative for the occurrence of landslides compared to gneiss. In most cases these effects are also found to be significant. Amphibolite is strongly negatively associated with the occurrence of landslides compared to gneiss at the regional level and in Kabonero but positively associated with landslides in Nyahuka. Mica schists also have complex behaviour, with a negative influence on landslide presence in Kabonero and Kyondo/Mahango but a positive effect in Bundibugyo and Nyahuka compared to the reference lithology, gneiss. Finally quartzite is found to mostly favour landslides albeit non-significantly.
To evaluate the difference between the regional susceptibility model and the local models, the susceptibility maps are pairwise displayed in Fig. 4. Overall, topographic patterns are consistent over the pairs, except for Nyahuka, where the strong imprint of TWI in the local model is evident. Furthermore, important visual discrepancies are present along lithological boundaries in Nyahuka and Kyondo. The local model for Nyahuka appears to be less influenced by lithology compared to the regional model. In Kyondo the opposite can be observed, with more pronounced lithological effect on the local susceptibility model than susceptibility assessment predicted by the regional model. This is in accordance with the findings from Table 3 where amphibolites are positively selected in the local Nyahuka model in contrast to the negative selection in the regional model, while mica schists are more often selected as a negative predictor in the local model for Kyondo than in the regional model and therefore contrast more with gneiss and quartzite. These visual discrepancies are also translated in a lower $\mathrm{AUC}_{\mathrm{ROC}}$ of the regional SRTM30 model when validated at the local levels individually compared to the $\mathrm{AUC}_{\mathrm{ROC}}$ of the regional model validated on the regional scale (i.e. using the data from all local levels combined), with the exception of Kabonero (Fig. 4). In the case of Bundibugyo and Nyahuka this decrease in AUC $_{\text {ROC }}$ is significant. In other words, models calibrated and validated at the local level generally outperform the regional model applied to that level and applying the regional model at the local level could result in a decrease of model reliability.

\subsection{Influence of separating landslide types}

Based on the findings above, the SRTM30 is applied for the separation of landslide types. The model fit for shallow landslides slightly decreases (average $\mathrm{AUC}_{\mathrm{ROC}}$ 0.67) compared to a model encompassing all landslides. For deep-seated landslides, the type separation improved the model performance with an increase of $\mathrm{AUC}_{\mathrm{ROC}}$ from 0.71 to 0.81 . The variables selected by both models are summarized in Table 4. Major differences between the model for shallow and deepseated landslides can be found in the response to lithology, topography and precipitation. With regard to lithology, rift alluvium is a significant explanatory variable for deep-seated landslides but less often so for shallow landslides. In contrast, the presence of amphibolite is a strong negative predictor for shallow landslides but rarely significant for deep-seated landslides. With regard to topography, the influence of tangent concave slopes becomes less important in the model for deep-seated landslides. Furthermore, the effect of annual average precipitation disappears in the model for deep-seated landslides. Finally, the percentage tree cover introduced in the model for shallow landslides is rarely selected. 


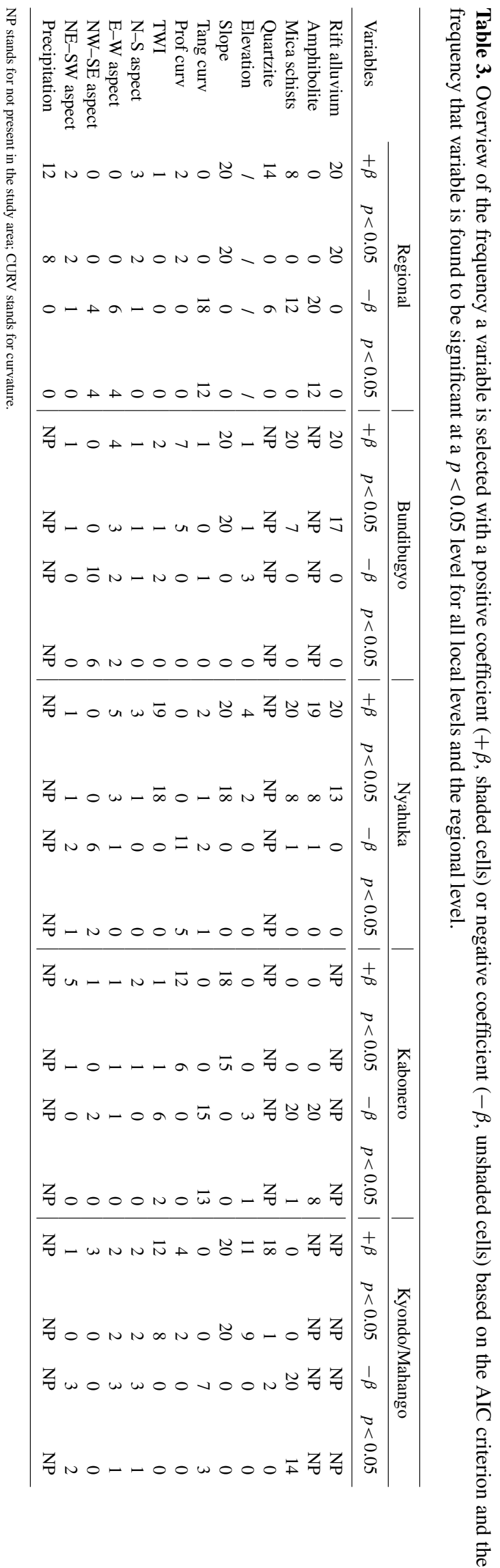




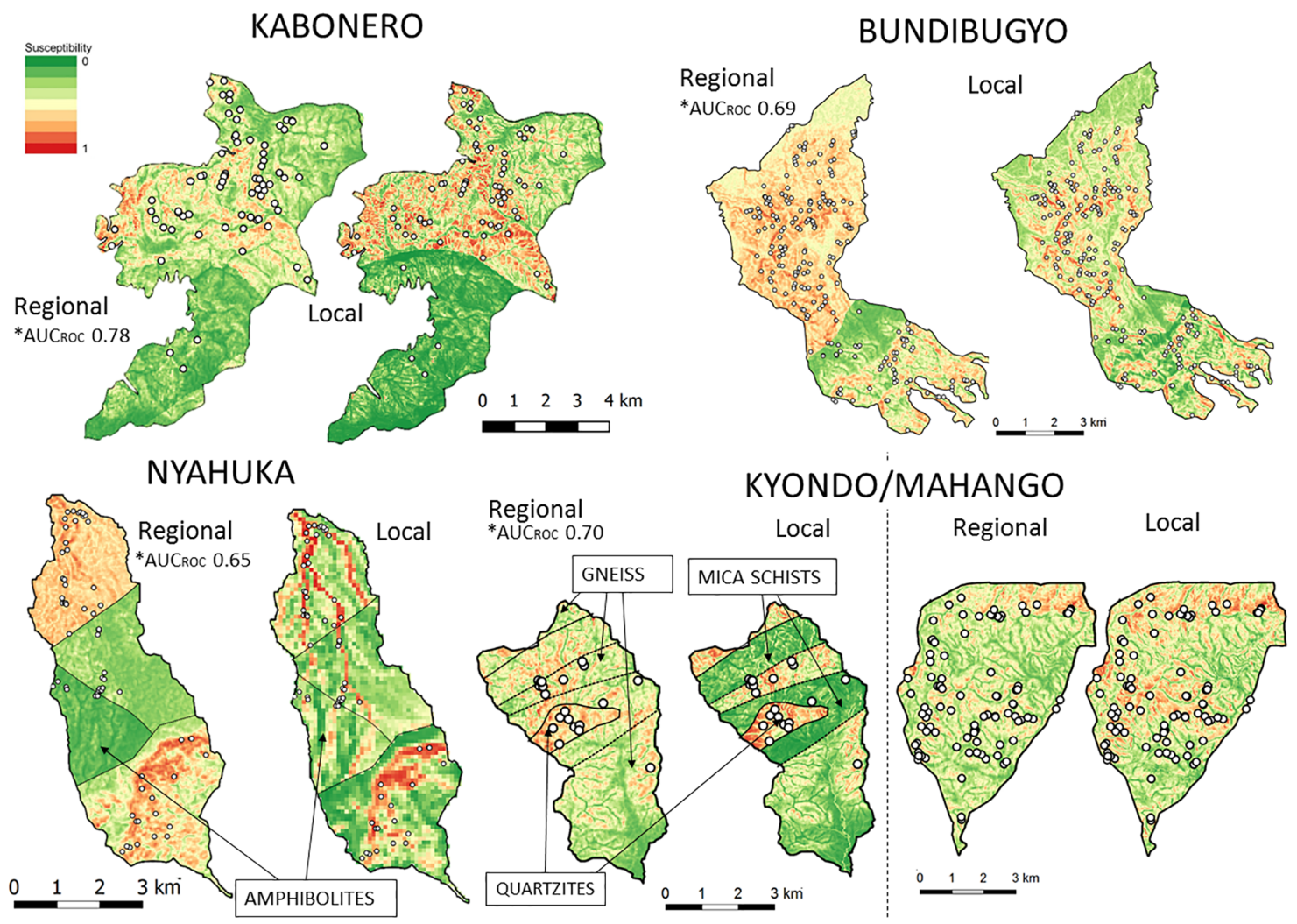

Figure 4. Pairwise comparison of the regional susceptibility model (left) and the local model (right) applied to the five case study areas. Dots represent landslide locations. Each of the models are achieved by averaging results of the 20 model runs for the selected variant. * Indicates the average performance in $\mathrm{AUC}_{\mathrm{ROC}}$ for the regional model as applied to the local study area.

Table 4. Overview of the frequency a variable is selected with a positive coefficient $(+\beta$, shaded cells) or negative coefficient $(-\beta$, unshaded cells) based on the AIC criterion and the frequency that variable is found to be significant on a $p<0.05$ level. This is given for the models at the regional level including all landslides, including only the shallow landslides and only the deep-seated landslides. The distinction between the latter two is made based on a $3 \mathrm{~m}$ threshold of the depth of the sliding plane.

\begin{tabular}{|c|c|c|c|c|c|c|c|c|c|c|c|c|}
\hline \multirow[b]{2}{*}{ Variables } & \multicolumn{4}{|c|}{ Regional } & \multicolumn{4}{|c|}{ Shallow slides regional } & \multicolumn{4}{|c|}{ Deep-seated slides regional } \\
\hline & $+\beta$ & $p<0.05$ & $-\beta$ & $p<0.05$ & $+\beta$ & $p<0.05$ & $-\beta$ & $p<0.05$ & $+\beta$ & $p<0.05$ & $-\beta$ & $p<0.05$ \\
\hline Rift alluvium & 20 & 20 & 0 & 0 & 16 & 3 & 4 & 0 & 20 & 20 & 0 & 0 \\
\hline Amphibolite & 0 & 0 & 20 & 12 & 1 & 0 & 19 & 11 & 5 & 0 & 15 & 1 \\
\hline Mica schists & 8 & 0 & 12 & 0 & 8 & 0 & 12 & 1 & 10 & 1 & 10 & 0 \\
\hline Quartzite & 14 & 0 & 6 & 0 & 16 & 0 & 4 & 0 & 6 & 0 & 9 & 0 \\
\hline Slope & 20 & 20 & 0 & 0 & 20 & 20 & 0 & 0 & 20 & 20 & 0 & 0 \\
\hline Tang curv & 0 & 0 & 18 & 12 & 0 & 0 & 15 & 11 & 0 & 0 & 7 & 4 \\
\hline Prof curv & 2 & 2 & 0 & 0 & 1 & 0 & 0 & 0 & 6 & 3 & 1 & 0 \\
\hline TWI & 1 & 0 & 0 & 0 & 3 & 2 & 0 & 0 & 2 & 0 & 0 & 0 \\
\hline $\mathrm{N}-\mathrm{S}$ (aspect) & 3 & 2 & 1 & 0 & 0 & 0 & 0 & 0 & 3 & 0 & 2 & 2 \\
\hline E-W (aspect) & 0 & 0 & 6 & 4 & 1 & 0 & 1 & 1 & 1 & 1 & 4 & 2 \\
\hline NW-SE (aspect) & 0 & 0 & 4 & 4 & 0 & 0 & 2 & 2 & 3 & 1 & 1 & 0 \\
\hline NE-SW (aspect) & 2 & 2 & 1 & 0 & 2 & 2 & 0 & 0 & 2 & 2 & 2 & 1 \\
\hline Precipitation & 12 & 8 & 0 & 0 & 14 & 14 & 0 & 0 & 2 & 1 & 2 & 0 \\
\hline Tree cover & NP & NP & NP & NP & 3 & 2 & 1 & 1 & NP & NP & $\mathrm{NP}$ & NP \\
\hline
\end{tabular}

NP stands for not provided as input to the model. 


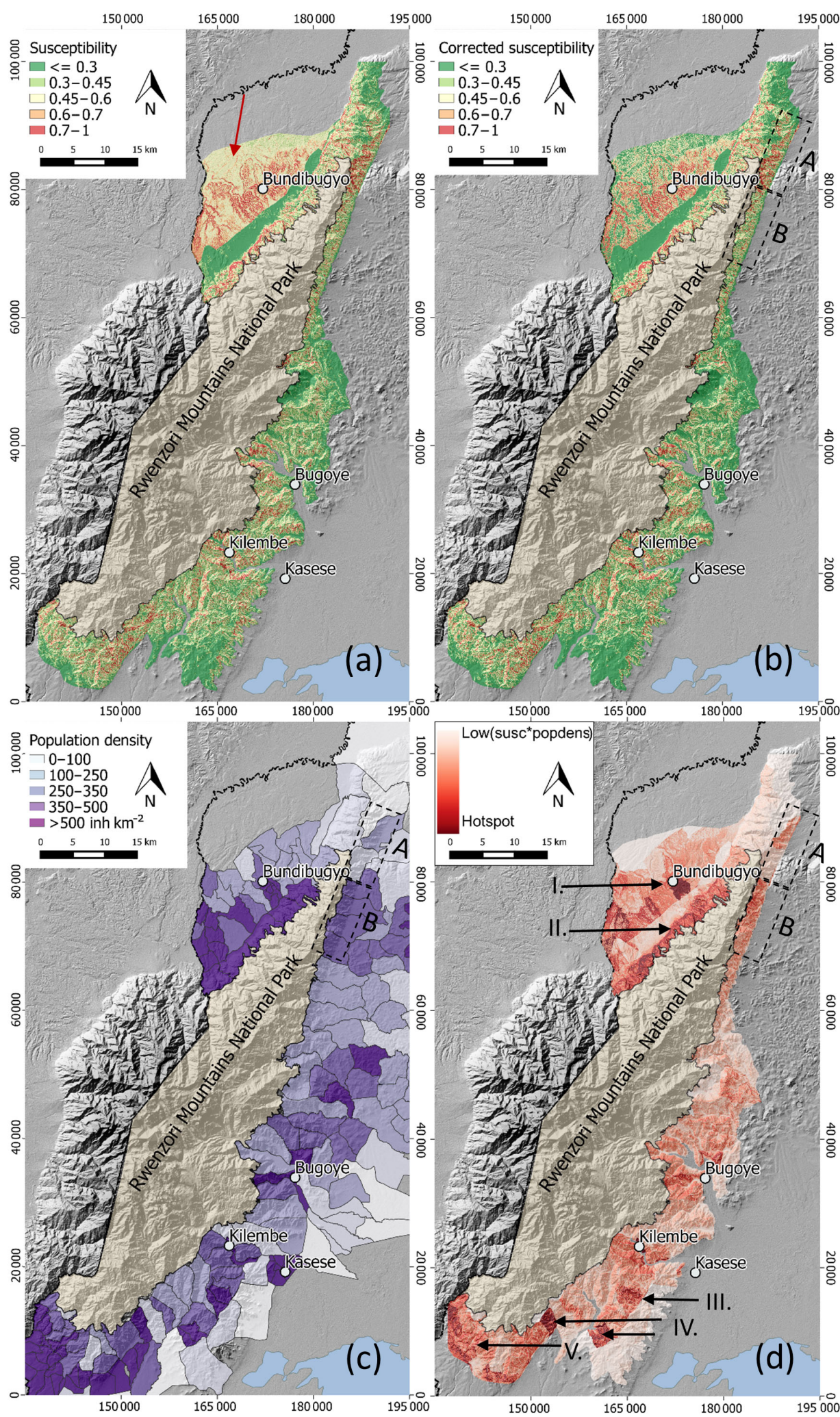

Figure 5. Landslide susceptibility (susc) and population density (pop dens) distribution in the Rwenzori Mountains' inhabited zone. (a) Landslide susceptibility (red arrow indicates artefacts in regional landslide susceptibility model). (b) Corrected landslide susceptibility. (c) Population density at parish level (source: UBOS, 2003). (d) Preliminary identification of landslide hotspots. A and B indicate polygons discussed in the text. I to $\mathrm{V}$ indicate particular hotspot locations elaborated in the text. 


\subsection{Regional landslide susceptibility and population distribution: identifying risk hotspots}

The regional susceptibility model is obtained by applying all 20 model simulations of the regional SRTM30 variant for all landslides and subsequent averaging (Fig. 5a). This approach seems to produce some artefacts in the northern sections of the lowland region (red arrow, Fig. 5a). Here, even at low slope gradient, medium to high landslide susceptibility values are assigned because of the occurrence of rift alluvium, strongly positively connected to landslides in the regional model. However, it could be expected that slopes below $5^{\circ}$ generally do not favour the occurrence of landslides in these lowlands (Jacobs et al., 2017). Here a slightly more conservative threshold of $3^{\circ}$ is considered, below which susceptibility values are reclassified. To avoid an abrupt change in susceptibility values at this threshold, the susceptibility in these mapping units is not set to zero but rescaled to values between 0 and 0.35 (i.e. rescaled to the lowest susceptibility class) according to their initial susceptibility value (Fig. 5b). This corrected landslide susceptibility map is combined with the rescaled population densities provided by UBOS (2003) (Fig. 5c) to produce a preliminary identification of potential landslide risk hotspots (Fig. 5d).

\section{Discussion}

\subsection{Effect of the model's spatial resolution and applied DEM on landslide susceptibility}

With regard to the spatial resolution selected, it has to be noted that an increase in model resolution does not necessarily influence the explanatory variables in equal ways: DEM resolution has potentially very different influences on the actual values derived for elevation, slope or other derivatives (Dewitte et al., 2010; Kervyn et al., 2008). In this case, a decrease of spatial resolution from 30 to $90 \mathrm{~m}$ in general decreased model performances. An increase in resolution from 20 to $10 \mathrm{~m}$, however, does not result in performance increases. This is in accordance with the concept of "optimal model complexity" in which an increase in information does not necessarily improve the model performances (Grayson et al., 2002) but instead performances tend to reach an optimum after which increasing data availability does not increase performance or it may even decrease it (Dewitte et al., 2010). This is in congruence with results found by Catani et al. (2013) and Lee et al. (2004).

Besides spatial resolution, the DEM source also influences the predictive power of the applied susceptibility model. The DEM based on optical imagery (ASTER) at the $30 \mathrm{~m}$ resolution never results in susceptibility models that significantly outperform those based on InSAR technology (SRTM and TanDEM-X), and on three levels the SRTM30 and TANDEMX30 significantly outperform the ASTER30 vari- ants. This is supported by earlier comparisons of the SRTM and ASTER DEMs by Kervyn et al. (2008), who found that the ASTER DEMs have lower vertical accuracies and are affected by more small-scale noise and resulting apparent topographic variability than the SRTM DEM. Similar findings are also found by Guth (2010) and Li et al. (2013).

\subsection{Variables influencing landslide susceptibility}

With the exception of Bundibugyo, all local models outperform the regional model in terms of $\mathrm{AUC}_{\mathrm{ROC}}$ and prediction rate. In general, by increasing the scale from regional to local level, more and more similar landslide processes are simulated within a single model. Because different landslide processes are controlled by different geo-environmental conditions, a downscaling to the local level can thus potentially result in a better performing model more tailored to the local conditions and sliding processes. An adverse effect can be observed in Bundibugyo, characterized by two very diverse sets of mass movements with deep-seated rotational slides in its lowlands and shallow soil - and debris slides in its highlands (Jacobs et al., 2016b). Therefore, downscaling from the regional to the local level for this case study area does not increase the model performance. Additionally, it is important to point out that the landslide sampling procedure used here assumes that the topography at the location of the depletion centroid was not altered. Particularly in the lowlands in Bundibugyo where large landslides are likely to leave important topographic signatures, this assumption could be violated, which could influence model performances. The increase in variation (or the decrease in stability) of $\mathrm{AUC}_{\mathrm{ROC}}$, sensitivity, and specificity and prediction curves at the local levels compared to the regional simulations can be explained by a decrease in landslide sample size for models built at the local level.

The visual analysis of the resulting susceptibility maps and the interpretation of their selected variables generally reveal similar patterns between the local and the regional landslide susceptibility model. However, important exceptions to this can be found in Nyahuka where there is a strong imprint of TWI on the local susceptibility map and in Nyahuka and Kyondo, where local and regional susceptibility differences are very pronounced for particular lithological groups. In Nyahuka, landslides in the lowland portion of the study area concentrate along rivers (Fig. 4). At the $90 \mathrm{~m}$ resolution, pixels with high TWI are large enough to include the depletion zone of the centroid, explaining the strongly positive influence of TWI in the local model and the exceptional preference for the SRTM90 variant. Additionally, in the regional model for Nyahuka, pixels on amphibolite have very low susceptibility values. This contrasts with the Nyahuka local model, where amphibolites are considered to favour the occurrence of landslides compared to gneiss. An adverse effect is noticeable in Kyondo, where mica schists are relatively less susceptible than what the regional model predicts. 
In Nyahuka, this unexpected lithological response of amphibolite could be due to the mapping accuracy of the lithological map. The lithological map used here is the most recent and most detailed map available for the region. However, the producers of the map report that field observations are limited to a section along the eastern foothills (Geological Survey of Finland, GTK, 2014). Previous lithological maps found in literature do not show the presence of an amphibolite group in the Nyahuka region (Bauer et al., 2010; Koehn et al., 2010; GTK, 2014). The landslides located on the amphibolite lithology in Nyahuka occur close to the lithological boundaries (Fig. 4) and therefore relatively small mapping errors could lie at the basis of this different apparent response of amphibolites in this region. For both Nyahuka and Kyondo the unexpected local lithological effects could also be due to regional differences between lithological groups not reflected in the classification system. It is possible that lithologies belonging to the same group will have different weathering patterns due to different climatic or tectonic regimes and thus different effects on landslide susceptibility. This is also stated by Dewitte et al. (2010), who point out that the relevance of a variable in a landslide susceptibility assessment depends not only on whether that variable plays a role in the landslide process itself but also on the quality of that variable. Finally, the local models in general outperform the regional model applied to the local levels (Fig. 4). This supports the observation of visual discrepancies between local and regional maps. In summary, the local maps are more tailored to represent the spatial probability of the sliding processes in that area and should therefore, wherever available, be preferred over the regional model. Furthermore, the regional model performance when applied to single local levels decreases significantly for two out of four local levels compared to the regional model performances when validating using the data of all the local levels combined, indicating that model results should be interpreted on the scale they were obtained.

\subsection{Separation of landslide types}

The separation of landslide types influences the predictive powers of susceptibility models improving the performances deep-seated landslides susceptibility zonation. This can be explained by the strong dependency of deep-seated landslides on lithology and in particular on rift alluvium, which is selected and found significant in all runs for each model considering only deep-seated slides. Rift alluvium in the Rwenzori Mountains is characterized by deep clay-rich deposits, lacking solid bedrock and therefore providing a medium for deep-seated shear planes.

Also for shallow landslides, the separation of landslide types allows us a better understanding of their regional controls despite a decrease in model performance. Notably the consideration of only shallow landslides allows us to better isolate topographic and climatic effects: the concentration of soil moisture in the landscape, the tangent curvature and the annual average precipitation distribution are important positive predictors of shallow landslides on the regional scale while their effects weaken or disappear in the model for deep-seated landslides. Finally, tree-cover fraction was expected to be a negative predictor for the occurrence of shallow landslides due to the potentially stabilizing effect of tree roots on the hillslopes, but this is not supported by the model results. This, however, does not a priori indicate that tree cover is not important predictor but might relate to limitations of the data sets itself. Firstly, as the tree-cover fraction is taken from the baseline year of 2000, it does not account for alterations preceding the most recent landslides in the inventory. Unfortunately, detailed and reliable temporal information on the mapped landslides is often not available, limiting the possibility to include land cover (change) as a reliable predictive variable. Secondly, in the tree-cover fraction classification, confusion exists between tree cover and cocoa, a common land use in the lowland areas of Bundibugyo and Nyahuka where nearly half of the shallow landslides occur, potentially resulting in an insensitivity of the regional model to tree-cover fraction.

\subsection{Regional landslide susceptibility and population distribution: identifying risk hotspots}

From Fig. 5d, which shows where high landslide susceptibility co-occurs with a high population density, some zones can be isolated, presenting apparent hotspots for landslide risk. First of all, in Bundibugyo and its surrounding parishes, population densities and landslide susceptibility are very high, leading to a potential hotspot (Fig. 5d, I). However, on the western flank of mountain's horst itself, a high landslide susceptibility is combined with high population densities (Fig. 5d, II). This observation is in contrast to the northeast flanks of the Rwenzori Mountains, where higher landslide susceptibilities are mostly combined with low population densities or vice versa (Fig. 5d, zones A and B, respectively). To the south-east of the Rwenzori Mountains, the area around Kilembe, located in the Nyamwamba Valley, appears to be a potential hotspot for landslide risk. Moreover, this valley is also known for its flash flood risk (Jacobs et al., 2016b). Currently, the construction of a hydropower station in the Kilembe Valley is ongoing. To what extent landslide and flood risks are taken into account in its design is unclear. South of the towns of Kasese and Kilembe, high landslide susceptibility values are again often combined with high population densities (Fig. 5d, III to V). Hotspot III largely coincides with Mahango sub-county: a region where landslides have regularly caused fatalities. South of the Rwenzori Mountains, e.g. hotspots IV and V, has so far been rarely researched. These areas are not systematically investigated nor did they appear as a landslide hotspot in archive studies (Jacobs et al., 2016a). In an effort to collect more landslide data in various remote areas of the Rwenzori region, a network of 20 inhabitants, referred to as geo-observers, is established. 
The geo-observers are trained to report on natural hazards occurring within their environment, such as landslides, by means of a digital questionnaire filled in using smartphone devices (VLIRUOS, 2017).

It needs to be stressed that this approach for identifying potential landslide risk hotspots entails major constraints and results should be considered as indicative and interpreted with extreme care. Evidently, the use of only landslide susceptibility and population density should as such not be considered as a risk estimate. In addition to this, the regional susceptibility model does not have a perfect performance and is, as stated above, an extrapolation for those areas outside the surveyed case studies and, as shown above, local landslide susceptibility patterns can differ from the pattern predicted by the regional susceptibility model. Landslide risk is also intrinsically connected to the size and speed of the landslide, parameters which are not accounted for here. Finally, withinparish distribution of population densities can significantly influence landslide risk, as within-parish spatial variation of landslide hazards can be expected and population dynamics since 2002 are not taken into account. Population density estimations could be improved by using satellite imagery for the mapping of built-up areas (Wu et al., 2005). The risk hotspot assessment presented here is not an estimate of landslide risk, but should be considered as a first indication of where research and policy priorities should be concentrated.

\section{Conclusions}

In this study, a regional landslide susceptibility assessment for the inhabited area of the Rwenzori Mountains is provided by analysing the effects of the considered scale (local assessments vs. regional assessment), topographic data sources and their spatial resolution as well as the separation of the landslide types. With regard to the DEM source, susceptibility models based upon DEMs derived from InSAR products (SRTM and TanDEM-X) tend to outperform the DEM derived from optical imagery (ASTER). While a resolution decrease of 30 to $90 \mathrm{~m}$ generally decreases model performances, an increase from 20 to $10 \mathrm{~m}$ does not improve model performances. The separation of landslide types at the regional level allows us to improve model skills for deep-seated landslides and to better understand the factors contributing to the susceptibility of shallow landslides. This study shows that at the regional level, slope and prevailing lithology strongly control landslide susceptibility. Shallow landslides seem to be more controlled by regional rainfall distribution and local runoff concentration in the landscape, while a strong effect of the presence of rift alluvium influences the occurrence of deep-seated landslides.
Recent research efforts have led to an increased availability of global, regional and even country-specific landslide susceptibility maps, including for data-scarce regions such as equatorial Africa (Broeckx et al., 2017; Redshaw et al., 2017; Stanley and Kirschbaum, 2017). In contrast, local and regional susceptibility assessments remain particularly rare in these regions. For the Rwenzori Mountains the local susceptibility assessments are generally better suited for representing the site-specific controlling mechanisms of landslides. In parallel to smaller-scale landslide susceptibility studies, adequate attention should therefore also be given to study landslide susceptibility at the local and regional levels. For the Rwenzori Mountains, the combination of regional landslide susceptibility with population density data allows us to visualize areas where landslide risk could be particularly high and where research and policy-oriented action needs to be taken.

Data availability. Landslide susceptibility maps presented in this study and landslide data used for their construction can be requested by contacting the corresponding author. 


\section{Appendix A: InSAR processing to construct the TanDEM-X DEM}

Over the last two decades, InSAR has been one of the main satellite-based tool used to evaluate ground displacements (Massonnet and Feigl, 1998; Bürgmann et al., 2000; Hanssen, 2001). This technique also allows us to construct DEMs and in particular the DLR (Deutsches Zentrum für Luft- und Raumfahrt - German Aerospace Center) TanDEM$\mathrm{X}$ mission was specifically designed to generate a consistent global DEM (Deo et al., 2013). Indeed, within the TanDEM$\mathrm{X}$ bi-static mode (Moreira et al., 2004), two satellites in close formation acquire the radar complex images (amplitude + phase components) of the same area at the same time. Each pixel of a SAR image is represented by a complex number: the amplitude corresponds to the backscattered energy by the surface illuminated by the radar microwave impulse while the phase equals a fraction of the complete wavelength (with a value between 0 and $2 \pi$ ). The phase difference from two SAR images (the interferogram) reveals variations in the distance between the ground and the satellites and appears as coloured fringes. Since the TanDEM-X images are acquired simultaneously no ground deformation or atmospheric changes will be observed between the two acquisitions and the interferogram contains only the topographyphase component and random noise (Bürgmann et al., 2000; Hanssen, 2001). For this work, each pair of the TanDEM-X SAR images is processed with the ENVI-SARscape $\odot$ software and these steps are followed to produce the DEMs:

1. The images are co-registered (i.e. geometrically overlapped) using the amplitude components.

2. The phase difference $\Delta \varphi$ (the interferogram) is evaluated and contain just two components:

$\Delta \varphi=\varphi_{\mathrm{t}}+\varphi_{\mathrm{n}}$,

where $\varphi_{\mathrm{t}}$ is the topographic-phase component (i.e. the $\mathrm{DEM}), \varphi_{\mathrm{n}}$ is the noise-phase component. For the $i$ th pixel, $\Delta \varphi_{i}$ ranges from 0 to $2 \pi$; by looking at the $\Delta \varphi$ of neighbour pixels and counting the fringe it is possible to evaluate the altitude. Indeed, each fringe corresponds to a variation on the altitude of the same value:

$h_{\mathrm{a}}=\left|\frac{\lambda R \sin (\theta)}{2 B_{\perp}}\right|$,

where $\theta$ is the local incidence angle, $h_{\mathrm{a}}$ is called altitude of ambiguity (Massonnet and Rabaute, 1993; Hanssen, 2001), $\lambda$ is the wavelength of the satellite $(\sim 3 \mathrm{~cm}$ for TanDEM-X), $R$ is the satellite altitude and $B_{\perp}$ is the perpendicular baseline between the two satellites.
3. To reduce the noise the image is multi-looked; i.e. the average over two pixels of SAR complex data is made in range $(x)$ and azimuth $(y)$. As the initial single look complex data have spatial resolutions of $\sim 2.5 \mathrm{~m} \times 2.5 \mathrm{~m}$, the resulting DEM is obtained at a resolution of $\sim 5 \mathrm{~m}$.

4. The SRTM-1arcsec DEM (Farr et al., 2000) is used to produce a synthetic interferogram; i.e. it is projected in radar looking geometry and then the altitude is converted in phase value. The synthetic interferogram is removed from the initial one to obtain the flattened interferogram. With TanDEM-X bi-static images, this difference represents the topographic changes compared to the SRTM DEM.

5. To further reduce the noise, an adaptive filter (Goldstein et al., 1998) is applied on the flattened interferogram to obtain the final filtered interferogram. The filter strength is evaluated for each pixel on the basis of the coherence $(\gamma)$ value: the lower coherence, the stronger the filter. The coherence is the cross-correlation value between the phase of one pixel and its neighbours within a window with preselected dimensions (in azimuth and range) and it ranges from 0 (not coherent) to 1 (complete coherence). This filter allows us to smooth the phase of the noisiest pixels since their coherence is low.

6. To convert the $\Delta \varphi$ values of the filtered interferogram in elevation data the unwrapping step is required. Here the minimum cost flow algorithm is used (Goldstein et al., 1988; Costantini, 1998). A 0.25 unwrapping threshold is used (all the pixels with coherence lower than this value are discarded).

7. The absolute calibrated and unwrapped phase is finally recombined with the synthetic phase associated with the SRTM DEM and it is converted to height. Then, the height map is geocoded using the SRTM DEM into the lat-long cartographic system (WGS-84 ellipsoid).

The vertical precision of the measurement, $\sigma_{z}$, is a function of the acquisition geometry and the standard deviation of the phase, $\sigma_{\phi}$;

$\sigma_{z}=\left(h_{\mathrm{a}} / 2 \pi\right) \times \sigma_{\phi}$,

where $h_{\mathrm{a}}$ is the altitude of ambiguity (Eq. 2). The standard deviation of the phase corresponds to the noise level of the interferogram and can be characterized, at first order, by the coherence parameter $\gamma$. For the Rwenzori InSAR DEMs produced from each image, the vertical error is on average $<7 \mathrm{~m}$.

Here nine and seven TanDEM-X couples in ascending and descending orbits, respectively, are used to construct two different DEMs that cover the entire Rwenzori region. These DEMs were compared to the SRTM-1 arcsec, and a horizontal shift was noticed that depends on the satellite acquisition 
geometry and is principally due to the geocoding process, to the error on the orbital data and to the horizontal error on the SRTM ( $\sim 20 \mathrm{~m}-$ Farr et al., 2000). Therefore, in order to limit this propagation, a mosaic of ascending and descending DEMs is constructed to cover the entire Rwenzori region. The seams of the mosaicked image do not run through the surveyed areas. For the inhabited region, the vertical error of this mosaic is on average $<3 \mathrm{~m}$. 
Competing interests. The authors declare that they have no conflict of interest.

Acknowledgements. This study was supported by the Belgium Science Policy (BELSPO) through the AfReSlide project BR/121/A2/AfReSlide in the BRAIN program entitled "Landslides in Equatorial Africa: Identifying culturally, technically and economically feasible resilience strategies", the RESIST project SR/00/3052 in the Stereo III program: REmote Sensing and In Situ detection and Tracking of geohazards and through the Vi-X project SR/00/150, in the Stereo II program (INTER Program, co-supported by FNR Luxembourg; grant NTI_INSA0525, DLR). Support was also received from the Research Foundation Flanders (FWO) for a long research stay abroad. Additional support was received from the VLIR South-Initiative project ZEIN2013Z145 entitled "Diagnosis of land degradation processes, their socio-economical and physical controls and implications in the Mt Rwenzori region" and project UG2017SIN208A105 entitled "Enhancing community-based natural resources and hazard management in Rwenzori Mountains". Wim Thiery was supported by an ETH Zurich postdoctoral fellowship (Fel-45 15-1) and acknowledges the Uniscientia Foundation and the ETH Zurich Foundation.

Edited by: Jean-Philippe Malet

Reviewed by: Marta-Cristina Jurchescu and Javier Hervás

\section{References}

Agresti, A.: Building and applying logistic regression models, Categorical Data Analysis, John Wiley \& Sons, Inc., Hoboken, NJ, USA, 2nd Edn., 211-266, https://doi.org/10.1002/0471249688.ch6, 2003.

Bauer, F. U., Glasmacher, U. A., Ring, U., Schumann, A., and Nagudi, B.: Thermal and exhumation history of the central Rwenzori Mountains, Western Rift of the East African Rift System, Uganda, Int. J. Earth Sci., 99, 1575-1597, https://doi.org/10.1007/s00531-010-0549-7, 2010.

Beven, K. J. and Kirkby, M. J.: A physically based, variable contributing area model of basin hydrology, Hydrol. Sci. Bull., 24, 43-69, 1979.

Brenning, A.: Spatial prediction models for landslide hazards: review, comparison and evaluation, Nat. Hazards Earth Syst. Sci., 5, 853-862, https://doi.org/10.5194/nhess-5-853-2005, 2005.

Broeckx, J., Vanmaercke, M., Duchateau, R., and Poesen, J.: A landslide susceptibility map of Africa, EGU General Assembly Conference Abstracts, Vol. 19, EGU2017-27, 2017.

Bürgmann, R., Rosen, P. A., and Fielding, E. J.: Synthetic aperture radar interferometry to measure Earth's surface topography and its deformation, Ann. Rev. Earth Pl. Sc., 28, 169-209, https://doi.org/10.1146/annurev.earth.28.1.169, 2000.

Catani, F., Lagomarsino, D., Segoni, S., and Tofani, V.: Landslide susceptibility estimation by random forests technique: sensitivity and scaling issues, Nat. Hazards Earth Syst. Sci., 13, 2815-2831, https://doi.org/10.5194/nhess-13-2815-2013, 2013.

Chang, K. T., Chiang, S. H., and Hsu, M. L.: Modeling typhoonand earthquake-induced landslides in a mountainous water- shed using logistic regression, Geomorphology, 89, 335-347, https://doi.org/10.1016/j.geomorph.2006.12.011, 2007.

Che, V. B., Kervyn, M., Suh, C. E., Fontijn, K., Ernst, G. G. J., del Marmol, M. A., Trefois, P., and Jacobs, P.: Landslide susceptibility assessment in Limbe (SW Cameroon): a field calibrated seed cell and information value method, Catena, 92, 8398, https://doi.org/10.1016/j.catena.2011.11.014, 2012.

Coe, J. A., Godt, J. W., Baum, R. L., Bucknam, R. C., and Michael, J. A.: Landslide susceptibility from topography in Guatemala, Landslides: Evaluation and Stabilization, edited by: Lacerda, W. A., Ehrlich, M., Fontura, S. A. B., Sayão, A. F. S., Taylor and Francis Group, London, 69-78, 2004.

Conover, W. J., Johnson, M. E., and Johnson, M. M.: A comparative study of tests for homogeneity of variances, with applications to the outer continental shelf bidding data, Technometrics, 23, 351361, https://doi.org/10.1080/00401706.1981.10487680, 1981.

Corominas, J., Van Westen, C., Frattini, P., Cascini, L., Malet, J. P., Fotopoulou, S., Catani, F., Van Den Eeckhaut, M., Mavrouli, O., Agliardi, F., Pitilakis, K., Winter, M.G., Pastor, M., Ferlisi, S., Tofani, V., Hervas, J., and Smith, J. T.: Recommendations for the quantitative analysis of landslide risk, B. Eng. Geol. Environ., 73, 209-263, https://doi.org/10.1007/s10064-013-0538-8, 2014.

Costantini, M.: A novel phase unwrapping method based on network programming, IEEE T. Geosci. Remote, 36, 813-821, https://doi.org/10.1109/36.673674, 1998.

Dai, F. C. and Lee, C. F.: Landslide characteristics and slope instability modeling using GIS, Lantau Island, Hong Kong, Geomorphology, 42, 213-228, 2002.

Dai, F. C. and Lee, C. F.: A spatiotemporal probabilistic modelling of storm induced shallow landsliding using aerial photographs and logistic regression, Earth Surf. Proc. Land., 28, 527-545, https://doi.org/10.1002/esp.456, 2003.

Deo, R., Manickam, S., Rao, Y. S., and Gedam, S. S.: Evaluation of interferometric SAR DEMs generated using TanDEM-X data, Geoscience and Remote Sensing Symposium (IGARSS), 2013 IEEE Int., 2079-2082, https://doi.org/10.1109/IGARSS.2013.6723221, 2013.

Dewitte, O., Chung, C. J., Cornet, Y., Daoudi, M., and Demoulin, A.: Combining spatial data in landslide reactivation susceptibility mapping: a likelihood ratio-based approach in W Belgium, Geomorphology, 122, 153-166, https://doi.org/10.1016/j.geomorph.2010.06.010, 2010.

Farr, T. G. and Kobrick, M.: Shuttle Radar Topography Mission produces a wealth of data, EOS, 81, 583-585, https://doi.org/10.1029/EO081i048p00583, 2000.

Fawcett, T.: An Introduction to ROC Analysis, Pattern Recogn. Lett., 27, 861-874, https://doi.org/10.1016/j.patrec.2005.10.010, 2006.

Fressard, M., Thiery, Y., and Maquaire, O.: Which data for quantitative landslide susceptibility mapping at operational scale? Case study of the Pays d'Auge plateau hillslopes (Normandy, France), Nat. Hazards Earth Syst. Sci., 14, 569-588, https://doi.org/10.5194/nhess-14-569-2014, 2014.

Glass, G. V.: Testing homogeneity of variances, Am. Educ. Res. J., 3, 187-190, https://doi.org/10.3102/00028312003003187, 1966.

Goetz, J. N., Guthrie, R. H., and Brenning, A.: Integrating physical and empirical landslide susceptibility models using generalized additive models, Geomorphology, 129, 376-386, https://doi.org/10.1016/j.geomorph.2011.03.001, 2011. 
Goldstein R. M., Zebker H. A., and Werner C. L.: Satellite radar interferometry: Two-dimensional phase unwrapping, Radio Sci., 23, 713-720, https://doi.org/10.1029/RS023i004p00713, 1988.

Goldstein, R. M. and Werner, C. L.: Radar interferogram filtering for geophysical applications, Geophys. Res. Lett., 25, 40354038, https://doi.org/10.1029/1998GL900033, 1998.

Gorsevski, P. V., Gessler, P. E., Foltz, R. B., and Elliot, W. J.: Spatial prediction of landslide hazard using logistic regression and ROC analysis, T. GIS, 10, 395-415, 2006.

Grayson, R. B., Blöschl, G., Western, A. W., and McMahon, T. A.: Advances in the use of observed spatial patterns of catchment hydrological response, Adv. Water Resour., 25, 1313-1334, https://doi.org/10.1016/S0309-1708(02)00060-X, 2002.

Grohmann, C. H.: Effects of spatial resolution on slope and aspect derivation for regional-scale analysis, Comput. Geosci., 77, 111117, https://doi.org/10.1016/j.cageo.2015.02.003, 2015.

GTK: Special Paper 55, Geology and Geodynamic Development of Uganda with Explanation of the $1: 1,000,000$ Scale Geological Map, http://tupa.gtk.fi/julkaisu/specialpaper/sp_055.pdf (last access: 30 June 2017), 2014.

GTK Consortium: Geological map of Uganda $1: 100,000$ Sheet No. 56 Fort Portal, No. 65 Karambi, No. 66 Kasese, 2012.

Guth, P. L.: Geomorphometric comparison of ASTER GDEM and SRTM, in: A special joint symposium of ISPRS Technical Commission IV \& AutoCarto in conjunction with ASPRS/CaGIS, 2010.

Guzzetti, F., Carrara, A., Cardinali, M., and Reichenbach, P.: Landslide hazard evaluation: a review of current techniques and their application in a multi-scale study, Central Italy, Geomorphology, 31, 181-216, 1999.

Guzzetti, F., Reichenbach, P., Ardizzone, F., Cardinali, M., and Galli, M.: Estimating the quality of landslide susceptibility models, Geomorphology, 81, 166-184, https://doi.org/10.1016/j.geomorph.2006.04.007, 2006.

Hansen, M. C., Potapov, P. V., Moore, R., Hancher, M., Turubanova, S. A., Tyukavina, A., Thau, D., Stehman, S. V., Goetz, S. J. , Loveland, T. R., Kommareddy, A., Egorov, A., Chini, L. , Justice, C. O., and Townshend, J. R. G.: High-Resolution Global Maps of 21st-Century Forest Cover Change, Science 342, 850853,2013

Hanssen, R. F.: Radar interferometry: data interpretation and error analysis, Vol. 2, Springer Netherlands, 2001.

Havenith, H. B., Strom, A., Caceres, F., and Pirard, E.: Analysis of landslide susceptibility in the Suusamyr region, Tien Shan: statistical and geotechnical approach, Landslides, 3, 3950, https://doi.org/10.1007/s10346-005-0005-0, 2006.

Heckmann, T., Gegg, K., Gegg, A., and Becht, M.: Sample size matters: investigating the effect of sample size on a logistic regression susceptibility model for debris flows, Nat. Hazards Earth Syst. Sci., 14, 259-278, https://doi.org/10.5194/nhess-14-2592014, 2014.

Heumann, C., Schomaker, C., and Shalabh, M.: Introduction to Statistics and Data Analysis: With Exercises, Solutions and Applications, Springer, Switzerland, 2017.

Hosmer, D. W. and Lemeshow, S.: Applied logistic regression, 2nd Edn., John Wiley \& Sons, New York, 2004.

Hussin, H. Y., Zumpano, V., Reichenbach, P., Sterlacchini, S., Micu, M., van Westen, C., and Bălteanu, D.: Different landslide sampling strategies in a grid-based bi-variate sta- tistical susceptibility model, Geomorphology, 253, 508-523, https://doi.org/10.1016/j.geomorph.2015.10.030, 2016.

Jacobs, L., Dewitte, O., Poesen, J., Delvaux, D., Thiery, W., and Kervyn, M.: The Rwenzori Mountains, a landslide-prone region?, Landslides, 13, 519-536, https://doi.org/10.1007/s10346015-0582-5, 2016a.

Jacobs, L., Maes, J., Mertens, K., Sekajugo, J., Thiery, W., Van Lipzig, N., Poesen, J., Kervyn, M., and Dewitte, O.: Reconstruction of a flash flood event through a multi-hazard approach: focus on the Rwenzori Mountains, Uganda, Nat. Hazards, 84, 851-876, https://doi.org/10.1007/s11069-016-2458-y, 2016 b.

Jacobs, L., Dewitte, O., Poesen, J., Maes, J., Mertens, K., Sekajugo, J., and Kervyn, M.: Landslide characteristics and spatial distribution in the Rwenzori Mountains, Uganda, J. Afr. Earth Sci., 134, 917-930, https://doi.org/10.1016/j.jafrearsci.2016.05.013, 2017.

Kervyn, M., Ernst, G. G. J., Goossens, R., and Jacobs, P.: Mapping volcano topography with remote sensing: ASTER vs. SRTM, Int. J. Remote Sens., 29, 6515-6538, 2008.

Kervyn, M., Jacobs, L., Maes, J., Bih Che, V., de Hontheim, A., Dewitte, O., Isabirye, M., Sekajugo. J., Kabaseke, C., Poesen, J., Vranken, L., and Mertens, K.: Landslide resilience in equatorial Africa: Moving beyond problem identification!, Belgeo, 1, 1-22, https://doi.org/10.4000/belgeo.15944, 2015.

Koehn, D., Lindenfeld, M., Rümpker, G., Aanyu, K., Haines, S., Passchier, C. W., and Sachau, T.: Active transsection faults in rift transfer zones: evidence for complex stress fields and implications for crustal fragmentation processes in the western branch of the East African Rift, Int. J. Earth Sci., 99, 1633-1642, https://doi.org/10.1007/s00531-010-0525-2, 2010.

Korup, O. and Stolle, A.: Landslide prediction from machine learning, Geology Today, 30, 26-33, https://doi.org/10.1111/gto.12034, 2014.

Lee, S., Choi, J., and Woo, I.: The effect of spatial resolution on the accuracy of landslide susceptibility mapping: a case study in Boun, Korea, Geosci. J., 8, 51-60, 2004.

Li, P., Shi, C., Li, Z., Muller, J. P., Drummond, J., Li, X., Li, J., Li, Y., and Liu, J.: Evaluation of ASTER GDEM using GPS benchmarks and SRTM in China, Int. J. Remote Sens., 34, 1744-1771, 2013.

Lowry, R.: Concepts \& Applications of Inferential Statistics, http: //vassarstats.net/textbook/ (last access: 20 January 2017), 2014.

Maes J., Kervyn, M., de Hontheim, A., Dewitte, O., Jacobs, L., Mertens, K., Vanmaercke, M., Vranken, L., and Poesen, J.: Landslide risk reduction measures: A review of practices and challenges for the tropics, Prog. Phys. Geog., 41, 191-221, https://doi.org/10.1177/0309133316689344, 2017.

Massonnet, D. and Feigl, K. L.: Radar interferometry and its application to changes in the Earth's surface, Rev. Geophys., 36, 441-500, https://doi.org/10.1029/97RG03139, 1998.

Massonnet, D. and Rabaute, T.: Radar interferometry: limits and potential. IEEE T. Geosci. Remote, 31, 455-464, https://doi.org/10.1109/36.214922, 1993.

Mertens, K., Jacobs, L., Maes, J., Kabaseke, C., Maertens, M., Poesen, J., Kervyn, M., and Vranken, L.: The direct impact of landslides on household income in tropical regions: A case study from the Rwenzori Mountains in Uganda, Sci. Total Environ., 550, 1032-1043, https://doi.org/10.1016/j.scitotenv.2016.01.171, 2016. 
METI/NASA: ASTER Global Digital Elevation Model by Ministry of Economy, Trade and Industry of Japan (METI) and the National Aeronautics and Space Administration (NASA), http: //asterweb.jpl.nasa.gov/gdem.asp (last access: 27 January 2017), 2009.

Metz, M., Mitasova, H., and Harmon, R. S.: Efficient extraction of drainage networks from massive, radar-based elevation models with least cost path search, Hydrol. Earth Syst. Sci., 15, 667678, https://doi.org/10.5194/hess-15-667-2011, 2011.

Moreira, A., Krieger, G., Hajnsek, I., Hounam, D., Werner, M., Riegger, S., and Settelmeyer, E.: TanDEM-X: a TerraSAR-X add-on satellite for single-pass SAR interferometry, Geoscience and Remote Sensing Symposium IGARSS'04 Proceedings IEEE International, 1000-1003, https://doi.org/10.1109/IGARSS.2004.1368578, 2004.

NASA JPL.: NASA Shuttle Radar Topography Mission Global 1 arc second. NASA LP DAAC, https://doi.org/10.5067/measures/srtm/srtmgl1.003 (last access: 20 January 2017), 2013.

Nefeslioglu, H. A., Gokceoglu, C., and Sonmez, H.: An assessment on the use of logistic regression and artificial neural networks with different sampling strategies for the preparation of landslide susceptibility maps, Eng. Geol., 97, 171-191, https://doi.org/10.1016/j.enggeo.2008.01.004, 2008.

Redshaw, P., Dijkstra, T., Free, M., Jordan, C., Morley, A., and Fraser, S.: Landslide Risk Assessment for the Built Environment in Sub-Saharan Africa, WLF: Advancing Culture of Living with Landslides, Springer, 5, 5-12, https://doi.org/10.1007/9783-319-53483-1_2, 2017.

Suzen M. L. and Doyuran, V.: Data driven bivariate landslide susceptibility assessment using geographical information systems: a method and application to Asarsuyu catchment, Turkey, Eng. Geol., 71, 303-321, https://doi.org/10.1016/S00137952(03)00143-1, 2004.

Stage, A. R. and Salas, C.: Interactions of elevation, aspect, and slope in models of forest species composition and productivity, Forest Sci., 53, 486-492, 2007.

Stanley, T. and Kirschbaum, D. B.: A heuristic approach to global landslide susceptibility mapping, Nat. Hazards, 87, 145-164, 2017.

Steger, S., Brenning, A., Bell, R., Petschko, H., and Glade, T., Exploring discrepancies between quantitative validation results and the geomorphic plausibility of statistical landslide susceptibility maps, Geomorphology, 262, 8-23, https://doi.org/10.1016/j.geomorph.2016.03.015, 2016.
Tian, Y., XiaO, C., Liu, Y., and Wu, L.: Effects of raster resolution on landslide susceptibility mapping: a case study of Shenzhen, Sci. China Ser. E, 51, 188-198, https://doi.org/10.1007/s11431008-6009-y, 2008.

Thiery, W., Davin, E., Panitz, H.-J., Demuzere, M., Lhermitte, S., and van Lipzig, N.: The impact of the African Great Lakes on the regional climate, J. Clim., 28, 4061-4085, https://doi.org/10.1175/JCLI-D-14-00565.1, 2015.

Thode, H. C.: Testing for Normality, Marcel Dekker, New York, 2002.

Tu, J. V.: Advantages and disadvantages of using artificial neural networks versus logistic regression for predicting medical outcomes, J. Clin. Epidemiol., 49, 1225-1231, https://doi.org/10.1016/S0895-4356(96)00002-9, 1996.

UBOS (Uganda Bureau of Statistics): Uganda National Household Survey 2002/2003, Ministry of Finance, Planning and Economic Development, Uganda, http://www.ubos.org (last access: 27 June 2014), 2003.

Van Den Eeckhaut, M., Vanwalleghem, T., Poesen, J., Govers, G., Verstraeten, G., and Vandekerckhove, L.: Prediction of landslide susceptibility using rare events logistic regression: a case-study in the Flemish Ardennes (Belgium), Geomorphology, 76, 392410, https://doi.org/10.1016/j.geomorph.2005.12.003, 2006.

Van Den Eeckhaut, M., Reichenbach, P., Guzzetti, F., Rossi, M., and Poesen, J.: Combined landslide inventory and susceptibility assessment based on different mapping units: an example from the Flemish Ardennes, Belgium, Nat. Hazards Earth Syst. Sci., 9, 507-521, https://doi.org/10.5194/nhess-9-507-2009, 2009.

VLIRUOS: Enhancing community-based natural resources and hazard management in Rwenzori Mountains, Ongoing project, http://www.vliruos.be/en/ongoing-projects/, last access: 30 June 2017.

Welch, B. L.: On the comparison of several mean values: an alternative approach, Biometrika, 38, 330-336, 1951.

Wu, S. S., Qiu, X., and Wang, L.: Population estimation methods in GIS and remote sensing: a review, Sci. Remote, 42, 80-96, 2005.

Yilmaz, I.: The effect of the sampling strategies on the landslide susceptibility mapping by conditional probability and artificial neural networks, Environ. Earth Sci., 60, 505-519, https://doi.org/10.1007/s12665-009-0191-5, 2010.

Zêzere, J. L., Pereira, S., Melo, R., Oliveira, S. C., and Garcia, R. A. C., Mapping landslide susceptibility using data-driven methods, Sci. Total Environ., 589, 250-267, 2017. 